\title{
Noninvasive Imaging of Endogenous Neural Stem Cell Mobilization In Vivo Using Positron Emission Tomography
}

\author{
Maria Adele Rueger, ${ }^{1,2 *}$ Heiko Backes, ${ }^{2 *}$ Maureen Walberer, ${ }^{1,2}$ Bernd Neumaier, ${ }^{2}$ Roland Ullrich, ${ }^{2}$ Marie-Lune Simard, ${ }^{1}$ \\ Beata Emig, ${ }^{1}$ Gereon Rudolf Fink, ${ }^{1,3}$ Mathias Hoehn, ${ }^{2}$ Rudolf Graf, ${ }^{2}$ and Michael Schroeter ${ }^{1,2}$ \\ ${ }^{1}$ Department of Neurology, University Hospital of Cologne, 50924 Cologne, Germany, ${ }^{2}$ Max Planck Institute for Neurological Research, 50931 Cologne, \\ Germany, and ${ }^{3}$ Institute of Neuroscience and Medicine (INM-3), Cognitive Neurology Section, Research Centre Juelich, 52425 Juelich, Germany
}

Neural stem cells reside in two major niches in the adult brain [i.e., the subventricular zone (SVZ) and the dentate gyrus of the hippocampus]. Insults to the brain such as cerebral ischemia result in a physiological mobilization of endogenous neural stem cells. Since recent studies showed that pharmacological stimulation can be used to expand the endogenous neural stem cell niche, hope has been raised to enhance the brain's own regenerative capacity. For the evaluation of such novel therapeutic approaches, longitudinal and intraindividual monitoring of the endogenous neural stem cell niche would be required. However, to date no conclusive imaging technique has been established. We used positron emission tomography (PET) and the radiotracer $3^{\prime}$-deoxy-3'- $\left.{ }^{18} \mathrm{~F}\right]$ fluoro-L-thymidine $\left(\left[{ }^{18} \mathrm{~F}\right] \mathrm{FLT}\right)$ that enables imaging and measuring of proliferation to noninvasively detect endogenous neural stem cells in the normal and diseased adult rat brain in vivo. This method indeed visualized neural stem cell niches in the living rat brain, identified as increased $\left[{ }^{18} \mathrm{~F}\right]$ FLT-binding in the SVZ and the hippocampus. Focal cerebral ischemia and subsequent damage of the blood-brain barrier did not interfere with the capability of $\left[{ }^{18} \mathrm{~F}\right]$ FLT-PET to visualize neural stem cell mobilization. Moreover, $\left[{ }^{18} \mathrm{~F}\right]$ FLT-PET allowed for an in vivo quantification of increased neural stem cell mobilization caused by pharmacological stimulation or by focal cerebral ischemia. The data suggest that noninvasive longitudinal monitoring and quantification of endogenous neural stem cell activation in the brain is feasible and that $\left[{ }^{18}\right.$ F]FLT-PET could be used to monitor the effects of drugs aimed at expanding the neural stem cell niche.

\section{Introduction}

The discovery of neural stem cells (NSCs) in the adult brain and their ability to self-renew and differentiate into tissue-appropriate functional cell types has raised intense scientific interest and the hope of radical new therapies for neurological diseases (Temple, 2001; Arvidsson et al., 2002; Nakatomi et al., 2002). In the adult brain, neuronal replacement mainly occurs in two areas [i.e., the subventricular zone (SVZ) adjacent to the lateral ventricles and the subgranular zone (SGZ) of the dentate gyrus in the hippocampus (Altman and Das, 1965; Kuhn et al., 1996; Doetsch et al., 1999)]. Expansion of the endogenous stem cell niche holds promise for the protection of damaged tissue, and possible cell replacement, and avoids the problems associated with tissue sampling and immunocompatibility inherent to transplantation strategies. Endogenous NSCs can be expanded in vivo via pharmacological agents that stimulate their proliferation and/or their survival. For example, application of growth factors to the rodent brain such as fibroblast growth factor 2 (FGF2) or epidermal growth factor (EGF) enhances endogenous NSC proliferation (Kuhn et al., 1997; Martens et al., 2002), whereas activation of

\footnotetext{
Received Dec. 9, 2009; revised March 3, 2010; accepted March 18, 2010.

This work was supported by the Koeln Fortune Program/Faculty of Medicine, University of Cologne, Germany (144/2007).

${ }^{*}$ M.A.R. and H.B. contributed equally to this work.

Correspondence should be addressed to Prof. Dr. med. Michael Schroeter, Department of Neurology, University Hospital of Cologne, Kerpener Strasse 62, 50924 Cologne, Germany. E-mail: Michael.Schroeter@uk-koeln.de. D0I:10.1523/JNEUROSCI.6092-09.2010

Copyright $\odot 2010$ the authors $\quad 0270-6474 / 10 / 306454-07 \$ 15.00 / 0$
}

the Notch1 receptor increases NSC survival (AndroutsellisTheotokis et al., 2006, 2008, 2009). Moreover, insults such as cerebral ischemia or various neurodegenerative diseases can result in mobilization of endogenous NSCs and their migration toward the compromised areas (Liu et al., 1998; Curtis et al., 2003; Jin et al., 2004; Zhang et al., 2008). To date, however, the assessment of endogenous NSC mobilization and migration requires the sacrifice of experimental animals for immunohistochemical evaluation because no method has yet been conclusively established to image endogenous NSCs in the brain in vivo.

Here we report for the first time that endogenous NSCs can be visualized in the living animal with positron emission tomography (PET) using the radiotracer $3^{\prime}$-deoxy- $3^{\prime}-\left[{ }^{18} \mathrm{~F}\right]$ fluoro-Lthymidine $\left(\left[{ }^{18} \mathrm{~F}\right] \mathrm{FLT}\right)$ that enables imaging and measuring of cell proliferation. We show that $\left[{ }^{18} \mathrm{~F}\right]$ FLT-PET not only detects endogenous NSCs in the healthy normal brain but can also be used to quantify NSC mobilization mediated by pharmacological stimulation or focal cerebral ischemia.

\section{Materials and Methods}

Radiochemistry. $\left[{ }^{18} \mathrm{~F}\right] \mathrm{FLT}$ was synthesized by nucleophilic substitution using benzoyl-protected anhydrothymidine according to the method of Machulla et al. (2000), with minor modifications, and as described previously (Jacobs et al., 2007). The synthesis was carried out using an automated synthesis module (Nuclear Interface). After ${ }^{18} \mathrm{~F}$ incorporation, the protected intermediate product was hydrolyzed with $1 \% \mathrm{NaOH}$ and the final product was isolated via preparative HPLC.

Cell culture. Neural stem cells were cultured from fetal rat cortex at embryonic day 14.5 according to the method of Johe et al. (1996). Cells 
were expanded as monolayer cultures in serum-free DMEM/F12 medium (Invitrogen) with N2 supplement (Invitrogen) and FGF2 (10 ng/ $\mathrm{ml}$, Invitrogen) for $5 \mathrm{~d}$ and were replated fresh or from frozen stocks at 10,000 cells per $\mathrm{cm}^{2}$. FGF2 was included throughout the experiments.

Neurons were dissected from fetal rat hippocampus at embryonic day 18.5 and grown as glia-free cultures in Neurobasal medium (Invitrogen) supplemented with L-Glutamine and B27 (both: Invitrogen).

Immunocytochemical stainings to characterize cell identity and morphology included the monoclonal antibodies $(\mathrm{mAb})$ against SOX2 (R\&D Systems) and MAP2 (Millipore).

To determine the ratio of proliferating cells, $10 \mu \mathrm{M}$ bromodeoxyuridine (BrdU; Fluka) was added to cultures for $6 \mathrm{~h}$, before cells were fixed with $4 \%$ PFA. Cells were stained with mAb against BrdU to identify proliferating cells (clone BU-33, dilution 1:100, Sigma). For antigenretrieval before staining, sections were incubated in $2 \mathrm{~N} \mathrm{HCl}$ for $30 \mathrm{~min}$. For visualization, FITC-labeled anti-mouse IgG was used (Invitrogen).

For the in vitro $\left[{ }^{18} \mathrm{~F}\right] \mathrm{FLT}$-experiments, $\left[{ }^{18} \mathrm{~F}\right] \mathrm{FLT}$ was added to cultures for $90 \mathrm{~min}$ at a concentration of $0.34 \mathrm{MBq} / \mathrm{ml}$. After thorough washing, counts per min (cpm) were analyzed in a $\gamma$-counter (1282 Compugamma, LKB Wallace). $\left[{ }^{18} \mathrm{~F}\right] \mathrm{FLT}$-uptake per single cell was determined by dividing this value by the number of cells.

All cell culture experiments were performed in triplicate.

Animals and surgery. All animal procedures were in accordance with the German Laws for Animal Protection and were approved by the local animal care committee and local governmental authorities. Spontaneously breathing male Wistar rats weighing 290-330 g were anesthetized with $5 \%$ isoflurane and maintained with $2.5 \%$ isoflurane in $65 \% / 35 \%$ nitrous oxide/oxygen.

Intracerebroventricular injections. One group of animals $(n=7)$ underwent a single intracerebroventricular injection of drugs. Of those, three received $5 \mu \mathrm{l}$ of a cocktail consisting of $6.7 \mu \mathrm{g}$ fibroblast growth factor 2 (FGF2), $6.7 \mu \mathrm{g}$ Delta-like 4 (Dll4), and $50 \mu \mathrm{g}$ insulin, whereas four animals received $5 \mu \mathrm{l}$ of a solution containing $6.7 \mu \mathrm{g}$ Dll4 and $50 \mu \mathrm{g}$ insulin only. Each animal was stereotactically injected with the respective cocktail into the left lateral ventricle, using the following stereotaxic coordinates: bregma anteroposterior $-0.9 \mathrm{~mm}$, mediolateral $+1.4 \mathrm{~mm}$, ventrodorsal $+3.8 \mathrm{~mm}$. As controls, $n=3$ rats were sham-injected (placebo group), and $n=3$ rats were not injected at all (untreated group).

Focal cerebral ischemia. In $n=3$ rats, permanent focal ischemia was produced by intraarterial injection of $\mathrm{TiO}_{2}$ spheres into the middle cerebral artery (MCA) as described elsewhere (Gerriets et al., 2004a). In brief, after exposure of the left common carotid artery (CCA), internal carotid artery (ICA), and external carotid artery (ECA), the ECA and the pterygopalatine branch of the ICA were ligated. Polyethylene tubing filled with saline and four $\mathrm{TiO}_{2}$ macrospheres of $0.315-0.355 \mathrm{~mm}$ in diameter was advanced through the CCA into the ICA until the tip of the tube was placed distal to the origin of the pterygopalatine artery. The macrospheres were advanced into the ICA by slow injection of $\sim 0.2 \mathrm{ml}$ saline.

In $n=4$ rats, transient focal ischemia was induced by temporary occlusion of the left MCA (MCAO) using a silicone-coated nylon suture that was introduced through a small arteriotomy of the CCA as described previously (Gerriets et al., 2004b). The filament was advanced into the ICA 18 to $23 \mathrm{~mm}$ beyond the carotid bifurcation until mild resistance indicated that the tip was lodged in the anterior cerebral artery blocking the blood flow to the MCA. Reperfusion was induced by withdrawing the suture after $90 \mathrm{~min}$.

After surgery, all animals were allowed to recover from the anesthesia and were put back into their home cages, where they were given access to food and water ad libitum. Starting on day 4 after intracerebroventricular injection of drugs or after induction of ischemia, respectively, the tracer BrdU was injected intraperitoneally once daily for $5 \mathrm{~d}$ at a dose of 50 $\mathrm{mg} / \mathrm{kg} / \mathrm{d}$ to label dividing cells.

Magnetic resonance imaging. In all animals subjected to stroke, MRI was performed $6 \mathrm{~d}$ after induction of ischemia to characterize the extent of the ischemic lesions and the disruption of the blood-brain barrier (BBB). Rats were anesthetized with isoflurane, and experiments were conducted on a 4.7 T BioSpec system (Bruker BioSpin) with a $30 \mathrm{~cm}$ bore horizontal magnet, equipped with a self-shielded gradient system (max gradient $100 \mathrm{mT} / \mathrm{m}$; rise time $<250 \mu \mathrm{s}$ ). Radio frequency transmission
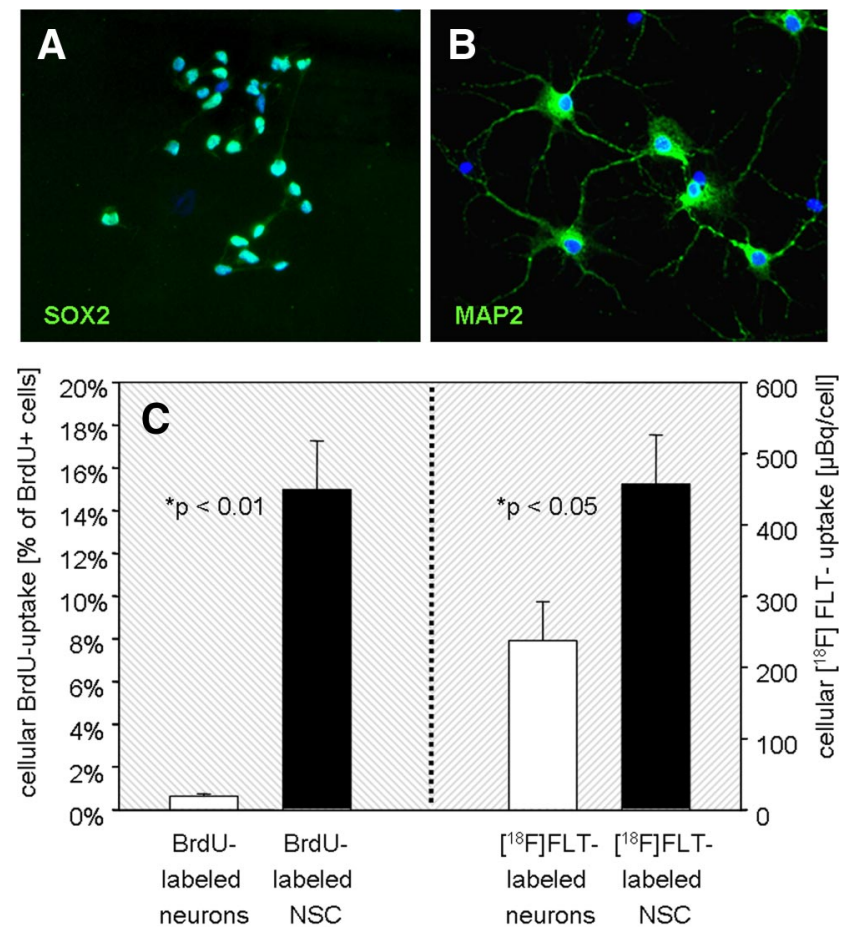

Figure 1. [ $\left.{ }^{18} \mathrm{~F}\right] \mathrm{FLT}$ labels proliferating NSCs in vitro. A, Fetal rat cortical NSCs grown in monolayer cultures expressed the transcription factor SOX2, verifying their undifferentiated state. B, Rat hippocampal neurons expressed the neuron-specific cytoskeletal protein MAP2. C, Left, Proliferating NSCs incorporated the thymidine analog BrdU, whereas nonproliferating neurons did not. Right, The radiolabeled thymidine $\left[{ }^{18} \mathrm{~F}\right] \mathrm{FLT}$ was significantly better incorporated into proliferating NSCs than into nonproliferating neurons (all values displayed as means \pm SEM).

was achieved with a Helmholtz coil (12 cm diameter), and the signal was detected with a $22 \mathrm{~mm}$ diameter surface coil. The animals were positioned prone in a dedicated cradle with stereotactic headholder, with the surface coil placed directly over the head. During scanning, body temperature and respiration rate were monitored and maintained with a combination of in-house equipment and DASYLab (DasyLab) version 9.0 software. Twelve contiguous 1 -mm-thick $\mathrm{T}_{2}$-weighted coronal images of the brain were acquired [repetition time (TR)/echo time (TE) $=$ $3000 / 14 \mathrm{~ms}, 16$ echoes, field of view $($ FOV $)=3.0 \mathrm{~cm}$, matrix $128 \times 128]$ using a multislice multiecho Carr-Purcell-Meiboom-Gill (CPMG) sequence. Following the $\mathrm{T}_{2}$-weighted sequence, rats received an intravenous bolus injection of $1 \mathrm{ml} / \mathrm{kg}$ Gadolinium-DTPA, and for up to $25 \mathrm{~min}$ later, T1-weighted coronal images of the brain were acquired (12 contiguous images at $1 \mathrm{~mm}$ slice thickness, TR/TE $=500 / 9 \mathrm{~ms}, 1$ echo, FOV = $3.0 \mathrm{~cm}$, matrix $128 \times 128)$ using a conventional multislice multiecho spin-echo sequence.

Positron emission tomography. Seven days after intracerebroventricular injection of drugs or after induction of ischemia, respectively, PETimaging was performed on a microPET Focus 220 scanner (Concorde Microsystems; 63 image planes; $1.5 \mathrm{~mm}$ full width at the half maximum). Animals were anesthetized with $5 \%$ isoflurane, maintained with $2 \%$ isoflurane in $65 \% / 35 \%$ nitrous oxide/oxygen, and placed in the scanner. Temperature was monitored using a rectal probe and maintained at $37 \pm$ $0.5^{\circ} \mathrm{C}$ by a thermostatically controlled water flow system (Medres). After a 10 min transmission scan for attenuation correction, rats received an intravenous bolus injection of $\left[{ }^{18} \mathrm{~F}\right] \mathrm{FLT}(1.0-2.2 \mathrm{mCi} / \mathrm{rat})$, and emission data were acquired for $90 \mathrm{~min}$. PET data were reconstructed in 22 time frames of $2 \times 60$ s, $2 \times 120$ s, $6 \times 240$ s, $12 \times 300$ s. The last six frames (minutes 60-90 after tracer injection) were averaged for quantification of PET data.

Image analysis. For image coregistration of MRI- and PET-data, the image analysis software VINCI was used, allowing for fast automated coregistration of all multimodal imaging data as previously described (Cízek et al., 2004). PET images were additionally coregistered to ana- 
tomical data of a three-dimensional (3D) rat brain atlas constructed from the brain slices presented by Swanson (Swanson, 2003). Based on the $3 \mathrm{D}$ anatomical data, ellipsoid Volumes of Interest (VOIs) measuring $4 \mathrm{~mm}^{3}$ were placed to cover the SVZ as well as the dentate gyrus region of the hippocampus. A standard uptake value (SUV) was calculated for each VOI, dividing maximal VOI activity by the decay-corrected injected radioactive dose per body weight. SUVs were individually determined and then averaged between animals within each group.

Immunohistochemistry. Nine days after intracerebroventricular injection of drugs or after induction of ischemia, respectively, rats were deeply anesthetized and decapitated. The brains were rapidly removed, frozen in isopentane, and stored at $-80^{\circ} \mathrm{C}$ before further histological and immunohistochemical processing. Ten-micrometer-thick adjacent serial coronal brain sections were cut at $500 \mu \mathrm{m}$ intervals and stained with $\mathrm{mAb}$ against $\mathrm{BrdU}$ to identify proliferating cells (clone BU-33, dilution 1:100, Sigma). For antigen-retrieval before staining, sections were microwave-heated in $0.01 \mathrm{M} \mathrm{ci-}$ trate buffer, $\mathrm{pH} 6.0$, for $5 \mathrm{~min}$, followed by $2 \mathrm{~N}$ $\mathrm{HCl}$ at $37^{\circ} \mathrm{C}$ for $30 \mathrm{~min}$. For visualization, the $\mathrm{ABC}$ Elite kit (Vector Laboratories) with diaminobenzidine (Sigma) as the final reaction product was used.

Statistical analysis. Descriptive statistics were performed with Microsoft Excel 2003 (Microsoft Corp.). Student $t$ tests and one-way ANOVA (with post hoc Bonferroni correction) were performed with SigmaStat 3.0 (SPSS). Statistical significance was set at $p<0.05$.

\section{Results}

\section{Proliferating NSCs incorporate}

$\left[{ }^{18} \mathrm{~F}\right]$ FLT

Fetal rat cortical NSCs were grown as monolayer cultures. Immunocytochemical staining for the transcription factor SOX2 verified the identity and morphology of undifferentiated cells (Fig. 1A). Glial-free hippocampal neuron cultures stained positive for the neuron-specific cytoskeletal protein MAP2 (Fig. $1 B$ ). To quantify the respective proliferation rates, NSCs and neurons were exposed to the thymidine analog BrdU for $6 \mathrm{~h}$, yielding 14.98\% BrdU-positive NSCs and $0.64 \%$ BrdU-positive neurons $(p<0.01)$ (Fig. $1 C$, left). To assess whether proliferating NSCs would also incorporate radiolabeled thymidine $\left[{ }^{18} \mathrm{~F}\right] \mathrm{FLT}$, cells were exposed to the tracer for $90 \mathrm{~min}$. Within that time, proliferating NSCs had incorporated $456.96 \mu \mathrm{Bq}$ per cell, whereas nonproliferating neurons incorporated only $237.37 \mu \mathrm{Bq}$ per cell $(p<0.05)$ (Fig. $1 C$, right).

\section{$\left[{ }^{18} \mathrm{~F}\right]$ FLT-PET visualizes endogenous NSCs in vivo}

Adult rats were systemically injected with radiolabeled thymidine $\left[{ }^{18} \mathrm{~F}\right] \mathrm{FLT}$ to visualize proliferating cells in the brain in vivo. Elevated tracer binding was detected in the subventricular zone as the major NSC niche of the adult brain (SVZ) (Fig. 2A). This corresponded to the BrdU accumulation in the SVZ verified ex vivo (Fig. $2 B$ ). Likewise, elevated $\left[{ }^{18} \mathrm{~F}\right] \mathrm{FLT}$ binding was detected
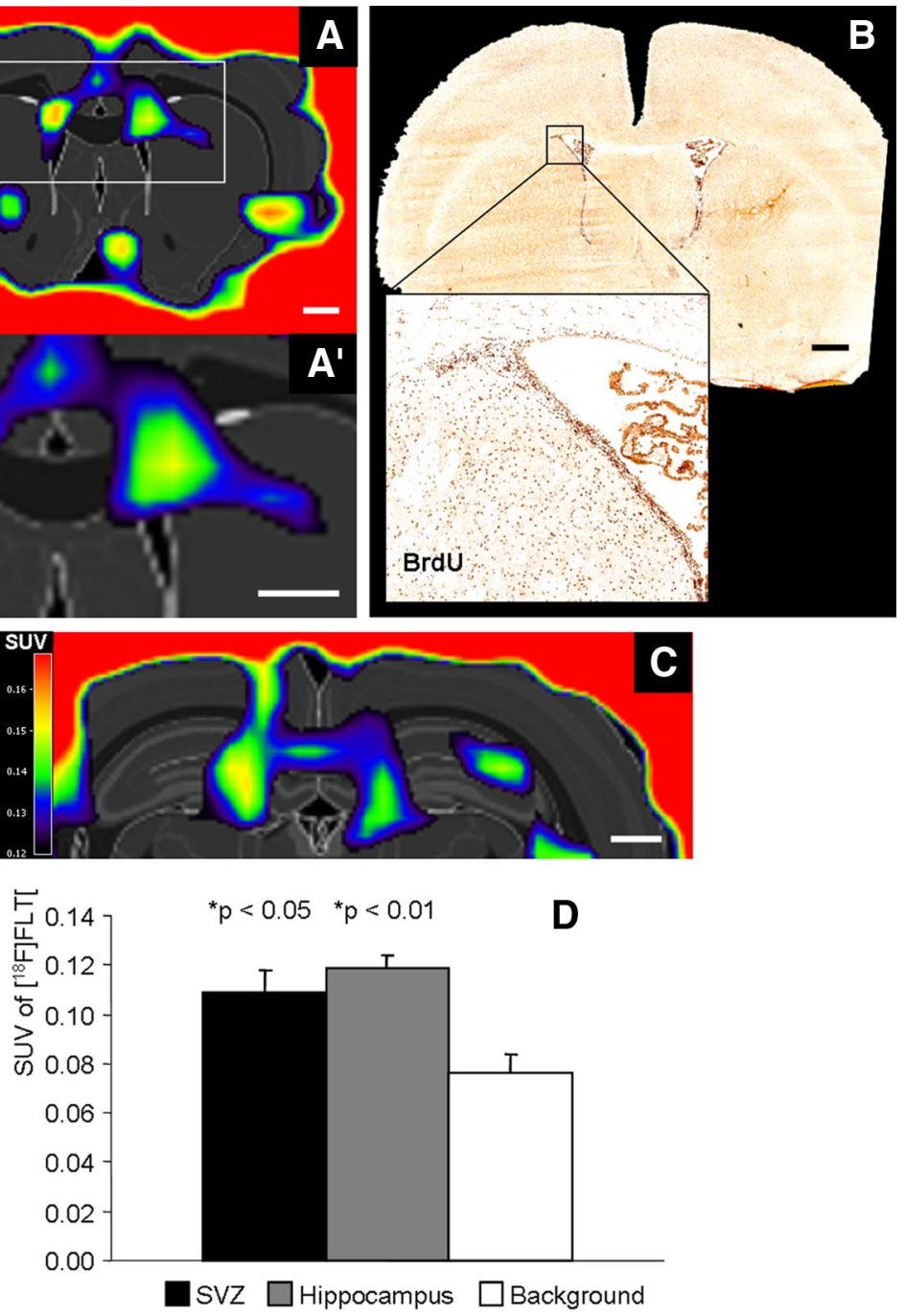

Figure 2. $\quad\left[{ }^{18} \mathrm{~F}\right] \mathrm{FLT}$-PET visualizes endogenous NSCs in vivo. A, Adult rats injected with [ $\left.{ }^{18} \mathrm{~F}\right] \mathrm{FLT}$ showed elevated tracer binding in the SVZ in vivo as a major NSC niche ([ $\left.{ }^{18} \mathrm{~F}\right] \mathrm{FLT}-\mathrm{PET}$ matched on MRI-atlas of rat brain; white box in upper image is magnified in in vivo ([ $\left.{ }^{18} \mathrm{~F}\right] \mathrm{FLT}$-PET matched on MRI-atlas of rat brain; scale bar, $\left.1 \mathrm{~mm}\right)$. D. Proliferation in both adult NSC niches, SVZ and hippocampus, was quantified in vivo by [ $\left.{ }^{18} \mathrm{~F}\right] \mathrm{FLT}$-binding, with significantly increased SUVs for [ $\left.{ }^{18} \mathrm{~F}\right] \mathrm{FLT}$ in both SVZ and hippocampus compared to background binding (values displayed as means \pm SEM).

in the hippocampus (Fig. 2C). Proliferation in both niches, SVZ and hippocampus, was quantified in vivo by $\left[{ }^{18} \mathrm{~F}\right] \mathrm{FLT}$ binding. SUVs for $\left[{ }^{18} \mathrm{~F}\right] \mathrm{FLT}$ in both SVZ $(0.11 \pm 0.01)$ and hippocampus $(0.12 \pm 0.01)$ were significantly higher than background $(0.08 \pm$ $0.01 ; p<0.05$ and $p<0.01$, respectively) (Fig. $2 D$ ).

Expansion of the proliferative zone around the lateral ventricles (SVZ) is quantitatively assessed by $\left[{ }^{18} \mathrm{~F}\right]$ FLT-PET in vivo

Mobilization of NSCs in the SVZ can be achieved by various pharmacological manipulations. We chose a single intracerebroventricular injection of a cocktail containing the growth factor FGF-2, the Notch1-ligand Dll4, and insulin, to expand the SVZ of adult rats (Fig. $3 A$ ). Nine days after intracerebroventricular injection of FGF2+Dll4+insulin, the width of the SVZ was significantly increased $(17.71 \mu \mathrm{m} \pm 3.03 ; p<0.001)$ compared to sham-injected $(3.83 \mu \mathrm{m} \pm 0.42)$ or untreated rats $(4.12 \mu \mathrm{m} \pm$ 0.63 ) (Fig. $3 A, B$ ). Intracerebroventricular injection of Dll4 plus 


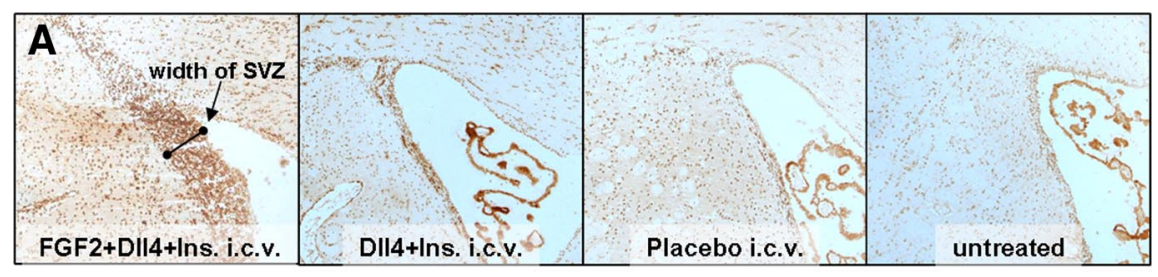

B
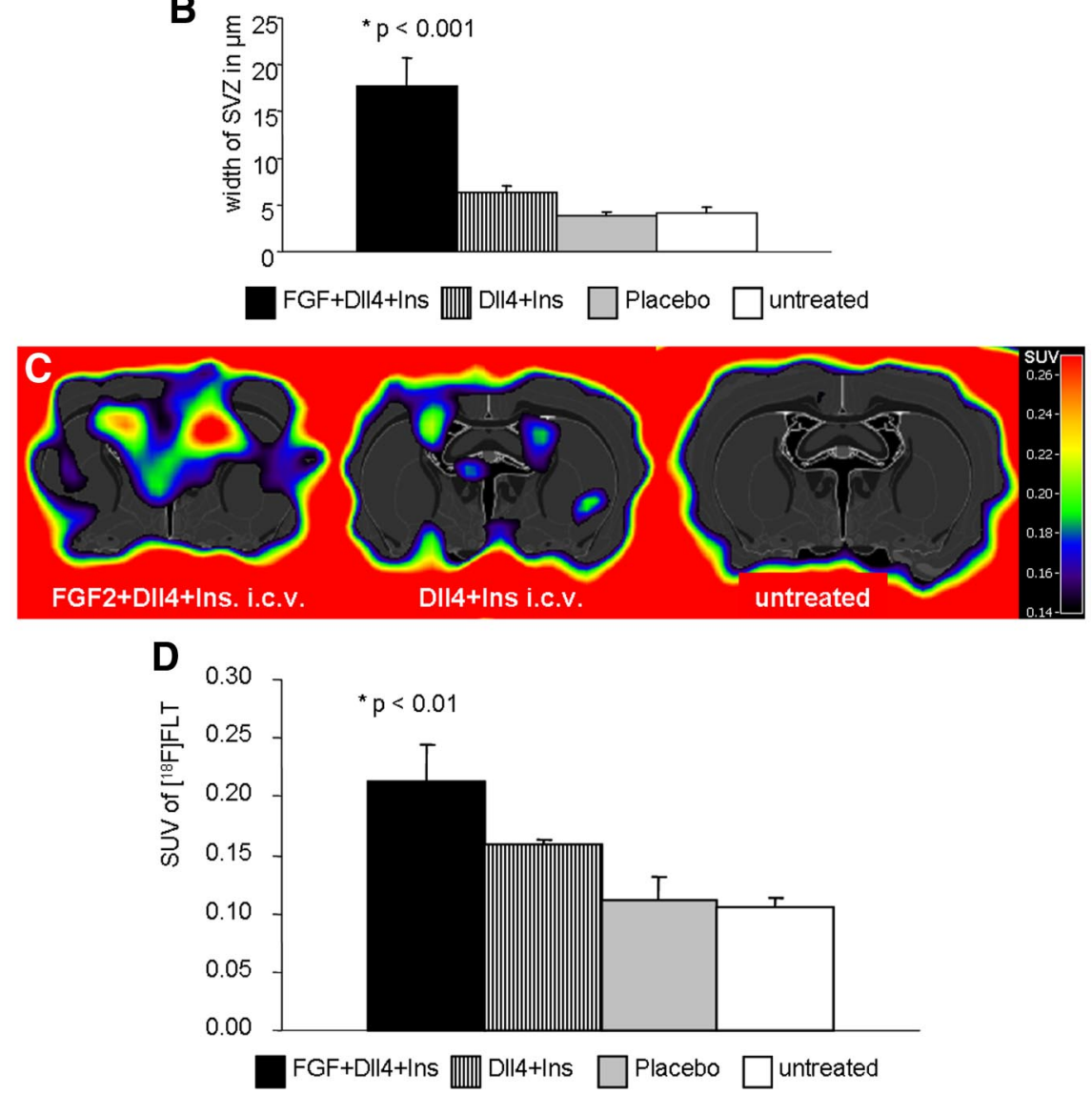

Figure 3. $\quad\left[{ }^{18} \mathrm{~F}\right] \mathrm{FLT}-\mathrm{PET}$ quantifies the expansion of the SVZ induced by pharmacological manipulations in vivo. A, Single intracerebroventricular injection of a cocktail containing DII4 and insulin, with or without addition of FGF2, mobilized NSCs and expanded the SVZ as quantified by BrdU-incorporation. $\boldsymbol{B}$, Histological quantitation of SVZ expansion. The width of SVZ was measured perpendicular to the ependymal surface as indicated in $\boldsymbol{A} 9 \mathrm{~d}$ after intracerebroventricular injection of vehicle, FGF2 + DII4 + insulin, or DII4 and insulin alone ( $p<0.001$ and $p<0.05$, respectively, compared to the pool of all control animals; values displayed as means \pm SEM). C, Single intracerebroventricular injection of a cocktail containing D\|l4 and insulin, with or without addition of FGF-2, mobilized NSCs and expanded the SVZ as visualized by $\left[{ }^{18} \mathrm{~F}\right] \mathrm{FLT}-\mathrm{PET}$. Please note the different pseudocolor scaling of SUV compared to Figure 2. The subtle [ $\left.{ }^{18} \mathrm{~F}\right] \mathrm{FLT}$ accumulation in naive animal (right), as displayed in Figure 2, is missed after adjusting the pseudocolor to higher SUV in pharmacologically stimulated animals (left, middle). D, Quantitation of SVZ expansion by $\left[{ }^{18} \mathrm{~F}\right] \mathrm{FLT}$ binding, $9 \mathrm{~d}$ after intracerebroventricular injection of vehicle, FGF2+DII4 + insulin, or DII4 and insulin alone (both $p<0.01$, compared to the pool of control animals; values displayed as means \pm SEM).

insulin without FGF2 also significantly expanded the SVZ, albeit to a lesser degree $(6.34 \mu \mathrm{m} \pm 0.76$; n.s.) (Fig. $3 A, B)$. $\left[{ }^{18} \mathrm{~F}\right] \mathrm{FLT}$ PET detected increased proliferation in the SVZ in vivo (Fig. $3 C$ ), with significantly elevated $\left[{ }^{18} \mathrm{~F}\right] \mathrm{FLT}$ binding after combined treatment with FGF2 + Dll4 + insulin (SUV $0.21 \pm 0.03 ; p<0.01$ ) compared to sham-injected (SUV $0.11 \pm 0.02$ ) or untreated rats (SUV $0.11 \pm 0.01$ ) (Fig. 3C,D). Similar to our findings ex vivo, Dll4 and insulin together increased proliferation to a lesser degree (SUV $0.16 \pm 0.004$; n.s.) (Fig. 3C,D). Correlating the histological measure of NSC proliferation to the PET data, we found that for every $1 \mu \mathrm{m}$ increase in the width of the SVZ, the SUV of FLT increased by $0.007(r=0.76, p<0.01)$.
Stroke-induced changes in proliferation are detected by $\left[{ }^{18}\right.$ F]FLT-PET

Permanent or transient focal cerebral ischemia was induced in the MCA territory of adult rats, causing characteristic signal alterations on $\mathrm{T}_{2}$-weighted MRI 1 week after induction of ischemia (Fig. $4 A$ ). Both stroke models caused lesions of similar extent. Tissue damage was verified histologically by $\mathrm{H} \& \mathrm{E}$ staining (Fig. $4 B$ ). Systemic injection of the contrast agent gadolinium revealed disruption of the BBB one week after stroke (Fig. 4C), and histological assessment of BBB disruption by IgG-staining ex vivo corresponded to MRI data (Fig. 4D). Within the ischemic area, $\left[{ }^{18} \mathrm{~F}\right]$ FLT binding was elevated 1 week after stroke (Fig. 4E,F). Pathophysiologically different models of focal ischemia (i.e., transient and permanent) caused similar proliferative activity in the damaged tissue, with both permanent (SUV $0.27 \pm 0.03$ ) and transient ischemia (SUV $0.27 \pm 0.05$ ) showing significantly elevated $\left[{ }^{18} \mathrm{~F}\right] \mathrm{FLT}$ binding compared to the unaffected contralateral side $(p<0.01$ and $p<0.05$, respectively) (Fig. $4 G$ ). Corresponding to the proliferative activity visualized by $\left[{ }^{18} \mathrm{~F}\right] \mathrm{FLT}-\mathrm{PET}$ in vivo, a multitude of cells within the ischemic area that incorporated BrdU were detected ex vivo (Fig. $4 H$ ).

\section{Stroke-induced mobilization of NSCs in SVZ and hippocampus are quantitatively assessed by $\left[{ }^{18} \mathrm{~F}\right]$ FLT-PET} One week after stroke, the exact coregistration of $\left[{ }^{18} \mathrm{~F}\right]$ FLT-PET and gadolinium-enhanced MRI allowed to delineate the $\left[{ }^{18} \mathrm{~F}\right]$ FLT binding in the SVZ (Fig. $5 A$ ) and the hippocampus (Fig. 5B). In both NSC niches, proliferative activity as assessed by $\left[{ }^{18} \mathrm{~F}\right]$ FLT-PET in vivo was elevated by about $35 \%$ as compared to nonstroke control animals, albeit this effect only reached statistical significance in the hippocampus $(p<0.05)$ (Fig. $5 C)$. To explore potential causes for interindividual variability in NSC mobilization, infarct sizes were determined volumetrically based on MRI data. Indeed, there was a strong correlation between the extent of ischemic damage and the magnitude of stem cell mobilization, especially in the SVZ $\left(R^{2}=\right.$ $0.89, p<0.05)$, but also in the hippocampus $\left(R^{2}=0.61, p<\right.$ 0.05 ) (Fig. 5D) with larger infarcts resulting in an increased $\left[{ }^{18} \mathrm{~F}\right]$ FLT binding in both the SVZ and the hippocampus.

\section{Discussion}

The discovery of NSCs in the adult brain nurtured the hope of using them to facilitate repair of damaged neural tissue. Initially, the main focus was on transplanting precursors that would then differentiate in vivo and replace lost neurons and glia (Renfranz et al., 1991; Brüstle et al., 1999). However, problems with the poor 
survival of transplanted cells, the lack of control over those cells in vivo, and issues with immunocompatibility limit their usefulness in transplantation studies. The mobilization of endogenous NSCs has obvious advantages, and achieving control over NSCs in vivo has been in the focus of research activities over the past years (Craig et al., 1996; Magavi et al., 2000; Nakatomi et al., 2002; Androutsellis-Theotokis et al., 2006). Increasing the number of NSCs in vivo was initially pursued by injecting growth factors such as FGF2 and EGF into the ventricles (Kuhn et al., 1997; Martens et al., 2002). Those ligands for tyrosine kinase receptors increase the number of stem cells by stimulating their proliferative activity, a mechanism that is hampered, however, with the inherent risk of causing cancer. Recently, a general model of stem cell expansion was reported in which activation of the Notch receptor leads to increased survival of NSCs instead of inducing proliferation (AndroutsellisTheotokis et al., 2006, 2008, 2009). Insults to the CNS such as cerebral ischemia or various neurodegenerative diseases lead to the mobilization of NSCs from the niches as an endogenous attempt of selfrepair (Liu et al., 1998; Curtis et al., 2003; Jin et al., 2004; Zhang et al., 2008). Cerebral ischemia in particular leads to a robust expansion of endogenous NSCs, as has been shown for various ischemia models including transient global ischemia (Liu et al., 1998), transient focal ischemia (Jin et al., 2001; Arvidsson et al., 2002), or permanent focal ischemia (Takasawa et al., 2002). Incidentally, NSCs seem to contribute to regeneration after stroke mainly by providing neuroprotection and trophic support, reducing neuroinflammation and inducing remodeling, but not so much by replacing lost neurons (for review, see Chopp et al., 2009). NSC expansion after stroke can be detected immunohistochemically by staining for proliferating cells. Microglia also proliferate after ischemic injury as part of the neuroinflammatory response (Denes et al., 2007). In the uninjured brain, however, resting microglia do not typically proliferate unlike NSCs. Here, we found that the degree of NSC activation is determined by the extent of the ischemic lesion, and not by its pathogenesis (i.e., permanent or transient ischemia). This may indicate that the event of early reperfusion per se does not have a key effect on the brain's regenerative response.

To date, assessment of NSC mobilization requires the killing of experimental animals for immunohistochemical evaluation, making intraindividual treatment studies impossible. The development of pharmacological agents aimed at mobilizing the NSC niche would therefore greatly benefit from a noninvasive imaging method allowing for endogenous NSC visualization and quantification in vivo.

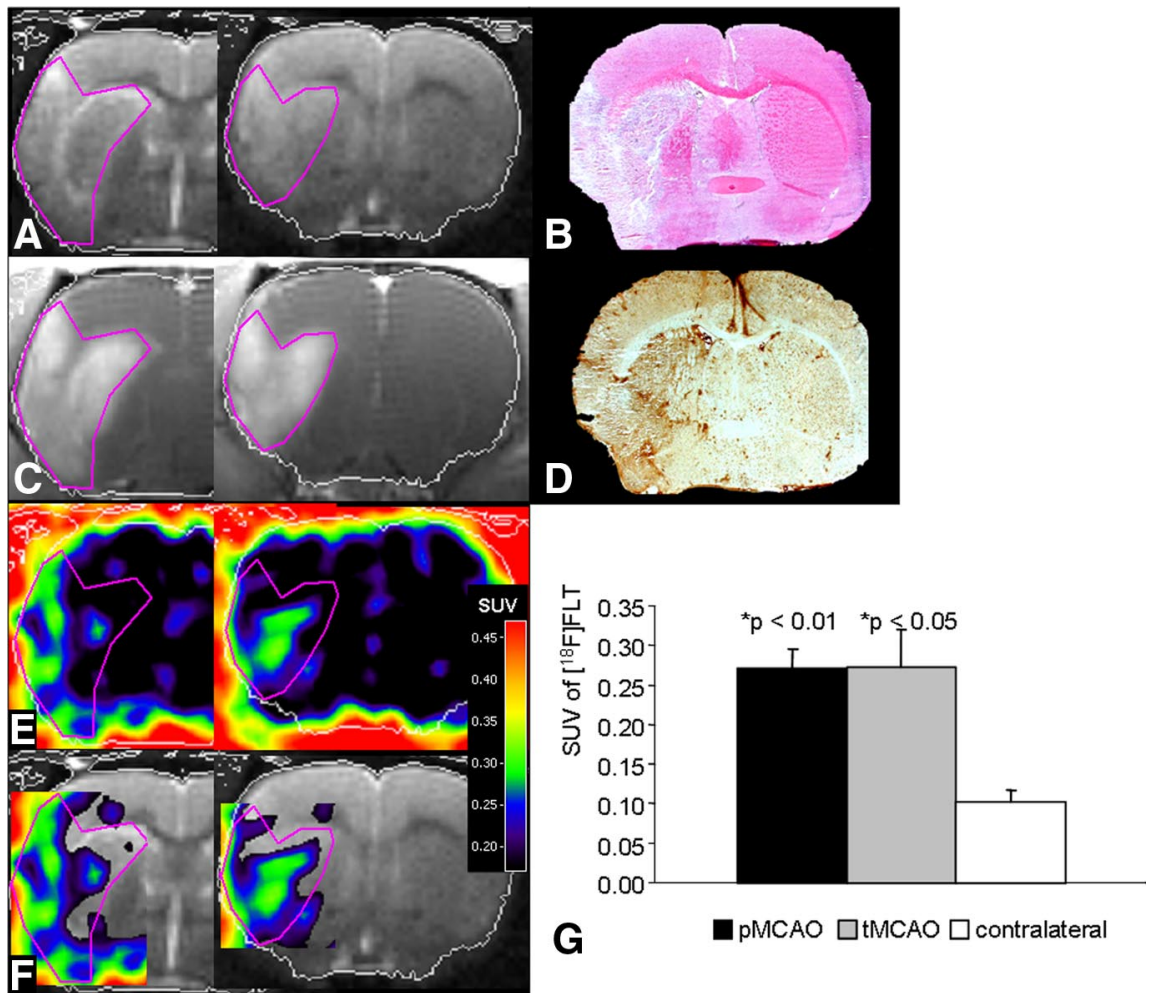

Figure 4. Stroke leads to enhanced proliferation within the ischemic lesion. $\boldsymbol{A}$, Focal cerebral ischemia caused characteristic 政 , proliferating cells within the infarct as the immunohistochemical correlate of $\left[{ }^{18} \mathrm{~F}\right] \mathrm{FLT}$ binding (objectives $\times 10, \times 100$ ).

Here, we used a basic principle of immunohistochemical NSC detection ex vivo to develop an in vivo imaging assay: in ex vivo studies, the thymidine analog BrdU was applied systemically and accumulated in dividing cells, thus labeling NSCs. We next systemically injected radiolabeled thymidine $\left(\left[{ }^{18} \mathrm{~F}\right] \mathrm{FLT}\right)$ and detected its accumulation in NSCs both in vitro and in vivo. Using both methods in parallel in cell culture to compare BrdU- and $\left[{ }^{18} \mathrm{~F}\right]$ FLT-accumulation in nonproliferating neurons with that of proliferating NSCs, we found that both markers were taken up by NSCs to a significantly greater extent. The effects observed were more pronounced for BrdU, most likely reflecting the longer incubation time of BrdU with the cells $(6 \mathrm{~h})$ compared to that of $\left.{ }^{18} \mathrm{~F}\right] \mathrm{FLT}(1.5 \mathrm{~h})$. Because of the short half-life of the PET tracer (110 $\mathrm{min})$, the incubation time with $\left[{ }^{18} \mathrm{~F}\right] \mathrm{FLT}$ could not be prolonged. More importantly, in the in vivo experiments $\left[{ }^{18} \mathrm{~F}\right]$ FLT also accumulated in NSCs, despite the relatively 

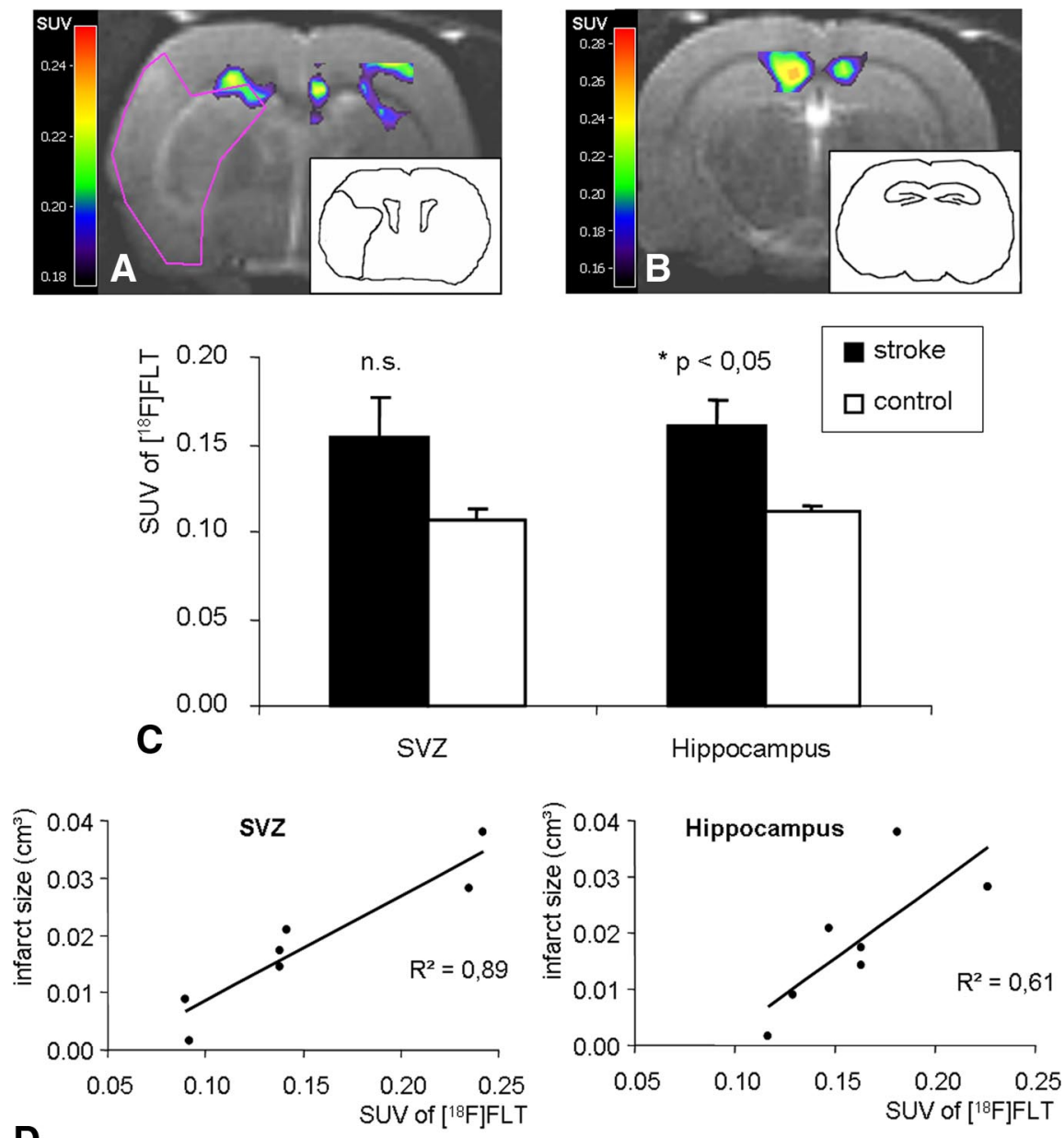

Figure 5. Stroke-induced expansion of the NSC niches can be distinguished with PET. A, Coregistration of $\left[{ }^{18} \mathrm{~F}\right] \mathrm{FLT}-\mathrm{PET}$ and gadolinium-enhanced MRI 1 week after stroke (infarct outlined in purple, for schematic overview see inset). $\left[{ }^{18} \mathrm{~F}\right] \mathrm{FLT}$ binding within the infarct core was repressed by image processing to emphasize comparatively weak tracer binding in the SVZ. B, Coregistration of $\left[{ }^{18} \mathrm{~F}\right] \mathrm{FLT}$-PET and gadolinium-enhanced MRI 1 week after stroke shows $\left[{ }^{18} \mathrm{~F}\right] \mathrm{FLT}$ binding within the hippocampus region (for schematic overview see inset). C, After stroke, $\left[{ }^{18} \mathrm{~F}\right] \mathrm{FLT}$ binding was upregulated in both SVZ and hippocampus compared to control animals (values displayed as means \pm SEM). $\boldsymbol{D}$, Infarct sizes determined volumetrically in vivo correlated well with the proliferative activity in both NSC niches as assessed by $\left[{ }^{18} \mathrm{~F}\right] \mathrm{FLT}$-PET.

short exposure time of 60 min before imaging data acquisition had to be started.

Shields et al. (1998) developed $\left[{ }^{18} \mathrm{~F}\right] \mathrm{FLT}$ as a tracer to image proliferation in vivo. $\left[{ }^{18} \mathrm{~F}\right] \mathrm{FLT}$ has since been extensively used in clinical oncology for the diagnosis and treatment monitoring of various tumors (Buck et al., 2002; Cobben et al., 2003; Francis et al., 2003; Wagner et al., 2003; Ullrich et al., 2008). The tracer is phosphorylated by the enzyme thymidine kinase 1 (TK1), which is expressed with the onset of the S-phase during DNA synthesis, its activity thus being a read-out for cellular proliferation. $\left[{ }^{18} \mathrm{~F}\right]$ FLT accumulation was shown to be a reliable measure of the salvage pathway of DNA synthesis (Rasey et al., 2002; Schwartz et al., 2003). After phosphorylation by TK1, $\left[{ }^{18} \mathrm{~F}\right] \mathrm{FLT}$ is trapped within the cell and can therefore be visualized by PET (Kong et al., 1992). To the best of our knowledge, this study is the first to suggest an application for $\left[{ }^{18} \mathrm{~F}\right] \mathrm{FLT}$ aside from oncology in stem cell research.

Several groups have previously attempted to establish imaging assays for endogenous NSCs, but to date very few approaches have proven feasible to date. Sumner et al. (2009) injected micron-sized particles of iron oxide into the lateral ventricle of rats and used MRI to monitor migration of NSCs from the SVZ along the rostral migratory stream into the olfactory bulb. Because of the high spatial resolution, MRI is indeed better suited than PET to precisely localize cells, but because of its lower sensitivity it requires a larger amount of labeled cells. Moreover, the labeling method of Sumner et al. (2009) involved injecting a large quantity of iron oxide particles into the ventricle, resulting in a considerable loss of signal and image distortion in the SVZ itself as well as in the midbrain region. Manganas et al. (2007) reported the discovery of a novel biomarker to visualize NSCs in both rodents and humans using proton magnetic resonance spectrosopy ( ${ }^{1} \mathrm{H}$-MRS). However, these findings have since been greatly debated (Friedman, 2008; Hoch et al., 2008; Jansen et al., 2008) and remain to be validated. Couillard-Despres et al. (2008) used optical imaging on transgenic mice expressing the bioluminescent protein luciferase under transcriptional control of the doublecortin promoter that is specific to neuronal precursors and young neurons. However, this technique is restricted to transgenic animals and is further limited by the low resolution of optical imaging in general.

Here we demonstrate that $\left[{ }^{18} \mathrm{~F}\right] \mathrm{FLT}$ PET can be used not only to visualize endogenous NSCs in adult rats in vivo but also to quantify the expansion of the NSC niche induced by pharmacological stimuli and stroke. Although the resolution of PET does not allow single-cell imaging or analysis of cytoarchitecture, this noninvasive technique is perfectly suited for intraindividual and longitudinal studies. We expect this method to be valuable for screening and developing novel agents aimed at expanding the endogenous NSC niche, as well as for monitoring the efficacy of such treatments in longitudinal studies on animal models of disease. Moreover, $\left[{ }^{18} \mathrm{~F}\right]$ FLT-PET could be used to clarify the role of NSCs in various CNS disorders at different disease stages.

\section{References}

Altman J, Das GD (1965) Autoradiographic and histological evidence of postnatal hippocampal neurogenesis in rats. J Comp Neurol 124 319-335.

Androutsellis-Theotokis A, Leker RR, Soldner F, Hoeppner DJ, Ravin R, Poser SW, Rueger MA, Bae SK, Kittappa R, McKay RD (2006) Notch signalling regulates stem cell numbers in vitro and in vivo. Nature 442:823-826

Androutsellis-Theotokis A, Rueger MA, Mkhikian H, Korb E, McKay RD (2008) Signaling pathways controlling neural stem cells slow progressive brain disease. Cold Spring Harb Symp Quant Biol 73:403-410.

Androutsellis-Theotokis A, Rueger MA, Park DM, Mkhikian H, Korb E, Poser SW, Walbridge S, Munasinghe J, Koretsky AP, Lonser RR, McKay RD (2009) Targeting neural precursors in the adult brain rescues injured dopamine neurons. Proc Natl Acad Sci U S A 106:13570-13575.

Arvidsson A, Collin T, Kirik D, Kokaia Z, Lindvall O (2002) Neuronal re- 
placement from endogenous precursors in the adult brain after stroke. Nat Med 8:963-970.

Brüstle O, Jones KN, Learish RD, Karram K, Choudhary K, Wiestler OD, Duncan ID, McKay RD (1999) Embryonic stem cell-derived glial precursors: a source of myelinating transplants. Science 285:754-756.

Buck AK, Schirrmeister H, Hetzel M, Von Der Heide M, Halter G, Glatting G, Mattfeldt T, Liewald F, Reske SN, Neumaier B (2002) 3-deoxy-3[(18)F] fluorothymidine-positron emission tomography for noninvasive assessment of proliferation in pulmonary nodules. Cancer Res 62:33313334 .

Chopp M, Li Y, Zhang ZG (2009) Mechanisms underlying improved recovery of neurological function after stroke in the rodent after treatment with neurorestorative cell-based therapies. Stroke 40:S143-S145.

Cízek J, Herholz K, Vollmar S, Schrader R, Klein J, Heiss WD (2004) Fast and robust registration of PET and MR images of human brain. Neuroimage 22:434-442.

Cobben DC, Jager PL, Elsinga PH, Maas B, Suurmeijer AJ, Hoekstra HJ (2003) 3'-18F-fluoro-3'-deoxy-L-thymidine: a new tracer for staging metastatic melanoma? J Nucl Med 44:1927-1932.

Couillard-Despres S, Finkl R, Winner B, Ploetz S, Wiedermann D, Aigner R, Bogdahn U, Winkler J, Hoehn M, Aigner L (2008) In vivo optical imaging of neurogenesis: watching new neurons in the intact brain. Mol Imaging $7: 28-34$.

Craig CG, Tropepe V, Morshead CM, Reynolds BA, Weiss S, van der Kooy D (1996) In vivo growth factor expansion of endogenous subependymal neural precursor cell populations in the adult mouse brain. J Neurosci 16:2649-2658.

Curtis MA, Penney EB, Pearson AG, van Roon-Mom WM, Butterworth NJ, Dragunow M, Connor B, Faull RL (2003) Increased cell proliferation and neurogenesis in the adult human Huntington's disease brain. Proc Natl Acad Sci U S A 100:9023-9027.

Denes A, Vidyasagar R, Feng J, Narvainen J, McColl BW, Kauppinen RA, Allan SM (2007) Proliferating resident microglia after focal cerebral ischaemia in mice. J Cereb Blood Flow Metab 27:1941-1953.

Doetsch F, Caillé I, Lim DA, García-Verdugo JM, Alvarez-Buylla A (1999) Subventricular zone astrocytes are neural stem cells in the adult mammalian brain. Cell 97:703-716.

Francis DL, Visvikis D, Costa DC, Arulampalam TH, Townsend C, Luthra SK, Taylor I, Ell PJ (2003) Potential impact of [18F]3'-deoxy-3'fluorothymidine versus [18F]fluoro-2-deoxy-D-glucose in positron emission tomography for colorectal cancer. Eur J Nucl Med Mol Imaging 30:988-994.

Friedman SD (2008) Comment on "Magnetic resonance spectroscopy identifies neural progenitor cells in the live human brain." Science 321:640.

Gerriets T, Stolz E, Walberer M, Müller C, Kluge A, Kaps M, Fisher M, Bachmann G (2004a) Middle cerebral artery occlusion during MR-imaging: investigation of the hyperacute phase of stroke using a new in-bore occlusion model in rats. Brain Res Protoc 12:137-143.

Gerriets T, Stolz E, Walberer M, Müller C, Rottger C, Kluge A, Kaps M, Fisher M, Bachmann G (2004b) Complications and pitfalls in rat stroke models for middle cerebral artery occlusion: a comparison between the suture and the macrosphere model using magnetic resonance angiography. Stroke 35:2372-2377.

Hoch JC, Maciejewski MW, Gryk MR (2008) Comment on "magnetic resonance spectroscopy identifies neural progenitor cells in the live human brain." Science 321:640.

Jacobs AH, Rueger MA, Winkeler A, Li H, Vollmar S, Waerzeggers Y, Rueckriem B, Kummer C, Dittmar C, Klein M, Heneka MT, Herrlinger U, Fraefel C, Graf R, Wienhard K, Heiss WD (2007) Imaging-guided gene therapy of experimental gliomas. Cancer Res 67:1706-1715.

Jansen JF, Gearhart JD, Bulte JW (2008) Comment on "Magnetic resonance spectroscopy identifies neural progenitor cells in the live human brain." Science 321:640.

Jin K, Minami M, Lan JQ, Mao XO, Batteur S, Simon RP, Greenberg DA (2001) Neurogenesis in dentate subgranular zone and rostral subventricular zone after focal cerebral ischemia in the rat. Proc Natl Acad Sci U S A 98:4710-4715.

Jin K, Peel AL, Mao XO, Xie L, Cottrell BA, Henshall DC, Greenberg DA (2004) Increased hippocampal neurogenesis in Alzheimer's disease. Proc Natl Acad Sci U S A 101:343-347.

Johe KK, Hazel TG, Muller T, Dugich-Djordjevic MM, McKay RD (1996)
Single factors direct the differentiation of stem cells from the fetal and adult central nervous system. Genes Dev 10:3129-3140.

Kong XB, Zhu QY, Vidal PM, Watanabe KA, Polsky B, Armstrong D, Ostrander M, Lang SA Jr, Muchmore E, Chou TC (1992) Comparisons of anti-human immunodeficiency virus activities, cellular transport, and plasma and intracellular pharmacokinetics of $3^{\prime}$-fluoro-3'-deoxythymidine and $3^{\prime}$-azido-3' -deoxythymidine. Antimicrob Agents Chemother 36:808-818.

Kuhn HG, Dickinson-Anson H, Gage FH (1996) Neurogenesis in the dentate gyrus of the adult rat: age-related decrease of neuronal progenitor proliferation. J Neurosci 16:2027-2033.

Kuhn HG, Winkler J, Kempermann G, Thal LJ, Gage FH (1997) Epidermal growth factor and fibroblast growth factor-2 have different effects on neural progenitors in the adult rat brain. J Neurosci 17:5820-5829.

Liu J, Solway K, Messing RO, Sharp FR (1998) Increased neurogenesis in the dentate gyrus after transient global ischemia in gerbils. J Neurosci 18:7768-7778.

Machulla HJ, Blocher A, Kuntzsch M, Piert M, Wei R, Grierson JR (2000) Simplified labeling approach for synthesizing $3^{\prime}$-deoxy-3' $-[18 \mathrm{~F}]$ fluorothymidine ([18F]FLT). J Radioanal Nucl Chem 243:843-846.

Magavi SS, Leavitt BR, Macklis JD (2000) Induction of neurogenesis in the neocortex of adult mice. Nature 405:951-955.

Manganas LN, Zhang X, Li Y, Hazel RD, Smith SD, Wagshul ME, Henn F, Benveniste H, Djuric PM, Enikolopov G, Maletic-Savatic M (2007) Magnetic resonance spectroscopy identifies neural progenitor cells in the live human brain. Science 318:980-985.

Martens DJ, Seaberg RM, van der Kooy D (2002) In vivo infusions of exogenous growth factors into the fourth ventricle of the adult mouse brain increase the proliferation of neural progenitors around the fourth ventricle and the central canal of the spinal cord. Eur J Neurosci 16:1045-1057.

Nakatomi H, Kuriu T, Okabe S, Yamamoto S, Hatano O, Kawahara N, Tamura A, Kirino T, Nakafuku M (2002) Regeneration of hippocampa pyramidal neurons after ischemic brain injury by recruitment of endogenous neural progenitors. Cell 110:429-441.

Rasey JS, Grierson JR, Wiens LW, Kolb PD, Schwartz JL (2002) Validation of FLT uptake as a measure of thymidine kinase- 1 activity in A549 carcinoma cells. J Nucl Med 43:1210-1217.

Renfranz PJ, Cunningham MG, McKay RD (1991) Region-specific differentiation of the hippocampal stem cell line HiB5 upon implantation into the developing mammalian brain. Cell 66:713-729.

Schwartz JL, Tamura Y, Jordan R, Grierson JR, Krohn KA (2003) Monitoring tumor cell proliferation by targeting DNA synthetic processes with thymidine and thymidine analogs. J Nucl Med 44:2027-2032.

Shields AF, Grierson JR, Dohmen BM, Machulla HJ, Stayanoff JC, LawhornCrews JM, Obradovich JE, Muzik O, Mangner TJ (1998) Imaging proliferation in vivo with [F-18]FLT and positron emission tomography. Nat Med 4:1334-1336.

Sumner JP, Shapiro EM, Maric D, Conroy R, Koretsky AP (2009) In vivo labeling of adult neural progenitors for MRI with micron sized particles of iron oxide: quantification of labeled cell phenotype. Neuroimage 44:671-678.

Swanson L (2003) Brain maps: structure of the rat brain. London, UK: Academic.

Takasawa K, Kitagawa K, Yagita Y, Sasaki T, Tanaka S, Matsushita K, Ohstuki T, Miyata T, Okano H, Hori M, Matsumoto M (2002) Increased proliferation of neural progenitor cells but reduced survival of newborn cells in the contralateral hippocampus after focal cerebral ischemia in rats. J Cereb Blood Flow Metab 22:299-307.

Temple S (2001) The development of neural stem cells. Nature 414 $112-117$.

Ullrich R, Backes H, Li H, Kracht L, Miletic H, Kesper K, Neumaier B, Heiss WD, Wienhard K, Jacobs AH (2008) Glioma proliferation as assessed by 3'-fluoro-3'-deoxy-L-thymidine positron emission tomography in patients with newly diagnosed high-grade glioma. Clin Cancer Res 14: 2049-2055.

Wagner M, Seitz U, Buck A, Neumaier B, Schultheiss S, Bangerter M, Bommer M, Leithäuser F, Wawra E, Munzert G, Reske SN (2003) 3'-[18F]fluoro-3'deoxythymidine ([18F]-FLT) as positron emission tomography tracer for imaging proliferation in a murine B-Cell lymphoma model and in the human disease. Cancer Res 63:2681-2687.

Zhang RL, Zhang ZG, Chopp M (2008) Ischemic stroke and neurogenesis in the subventricular zone. Neuropharmacology 55:345-352. 